\title{
Degradation of bisphenol A by different fungal laccases and identification of its degradation products
}

Dalel Daâssi*a,b, Alicia Prietoc ${ }^{\text {c }}$ Héla Zouari-Mechichia , María Jesús Martínez ${ }^{c}$, Moncef Nasri $^{\mathrm{a}}$, Tahar Mechichi ${ }^{\mathrm{a}}$

aLaboratory of Enzyme Engineering and Microbiology, Ecole Nationale d'Ingénieurs de Sfax, University of Sfax, Route de Soukra Km 4,5, BP 1173, 3038 Sfax, Tunisia.

${ }^{\mathrm{b}}$ Department of Biology, Faculty of Sciences and Arts, Khulais, University of Jeddah, Jeddah, Saudi Arabia.

'Centro de Investigaciones Biológicas (CIB-CSIC), Ramiro de Maeztu 9, E-28040

Madrid, Spain.

* Corresponding authors:

Dalel Daâssi (daleldaassi@yahoo.com)

Tahar Mechichi (tahar.mechichi@enis.rnu.tn ) 


\section{Abstract}

Different fungal laccases were used as biocatalysts for the biotransformation of bisphenol A (BPA). The quantitative analysis by gas chromatography-mass spectrometry (GC-MS) showed that BPA is more rapidly oxidized by Coriolopsis gallica laccase among the different fungal laccases tested. Carboxylic acid derivatives such as tartaric acid was found as BPA degradation products resulting from reactions catalyzed by $1 \mathrm{U} \mathrm{ml}^{-1}$ of laccase from $C$. gallica in the presence of $1 \mathrm{mM}$ of the laccasemediator 1-hydroxybenzotriazole (HBT), while $\beta$-hydroxybutyric acid resulted from oxidative reactions without HBT. BPA was completely removed within $3 \mathrm{~h}$ and pyroglutamic acid was found as a supplementary oxidative degradation product from HBT when identified by GC-MS. Laccase played a critical role in BPA biodegradation and catalyzed a cross-coupling reaction.

Key words : Bisphenol A, Laccases, Biodegradation, Identification , Intermediates, pathway. 


\section{Introduction}

Bisphenol A (BPA) is one of the most widely manufactured chemical in the world due to its broad spectrum of applications and growing demand. Around $95 \%$ of BPA is used for the production of synthetic polymers including epoxy resins and polycarbonates (Flint et al., 2012). The final products are used as coatings on cans, powder paints, additives in thermal paper, dental fillings and as antioxidants in plastics.

However, BPA has been identified as an Endocrine Disrupting Chemical (EDC) by the US Environmental Protection Agency (EPA) and the World Wide Fund for Nature (WWF) and has been declared as a social, environmental and global issue (Mohapatra et al., 2010). EDCs are synthetic chemicals that may interfere with the body 's endocrine system and produce adverse developmental, reproductive, neurological, and immune effects in both humans and wildlife (Chen et al., 2008; Muelle and Heger, 2013). The health effects from exposure to BPA have been investigated elsewhere (Sun et al., 2013).

Thus, during the last years, the degradation of BPA has been extensively studied. Advanced oxidation processes, such as Fenton reaction (Mohapatra et al., 2011), ozonation (Wang et al., 2014), photocatalytic oxidation ( Kuo et al., 2014; Tan et al., 2015), ultrasonic oxidation ( Yu et al., 2014) and combined techniques ( Nie et al., 2014), can efficiently oxidize BPA owing to the production of hydroxyl radicals. However, these technologies present several important disadvantages since they are time-consuming methodologies, have high costs, and lead to toxic residues (Michałowicz, 2014). 
Furthermore, several combined anaerobic and aerobic microbial treatments have been suggested to enhance the degradation of BPA using bacterial consortia (Eio et al., 2014; Kamaraj et al., 2014) and the acclimation strategy ( Fischer et al., 2010). However, the acclimation process to a xenobiotic, such as BPA, could interfere with the normal biodegradable substrates (Ferro Orozco et al., 2013) and many bacterial metabolic pathways will be involved in the biodegradation process (Eio et al., 2014). Ligninolytic fungi have been studied as a possible agent with extensive biodegradation properties for several pollutants because of the production of nonspecific oxidative enzymes, i.e. manganese peroxidase (MnP), lignin peroxidase (LiP), versatile peroxidase (VP) or laccases (Lac) (Reddy, 1995; Gianfreda et al., 2006).

Among these oxidative enzymes, laccases from the white rot fungus (WRF) have attracted more attention in treatment of EDCs at low concentrations due to its high reactivity and selectivity. Chairin et al. (2013) reported the efficiency of laccase from Trametes polyzona in the biodegradation of BPA. Moreover, studies on laccases of the basidiomycetes Trametes villosa (Fukuda et al., 2001), Coriolopsis polyzona (Cabana et al., 2007), Trametes polyzona (Chairin et al., 2013 ), Trametes versicolor, Polyporus pinisitus (Kim et al., 2008; Margot et al., 2013 ), and Grifola frondosa (Nitheranont et al., 2011), as well as laccases from other basidiomycetes (Tanaka et al., 2000; Kim and Nicell, 2006), revealed the potential of these oxidative enzymes for BPA degradation. Although laccases have lower redox potential, their expanded role on non-phenolic compounds, in the presence of a low molecular mass mediator, as well as their utilization of oxygen, a non-limited electron acceptor for their catalytic activity, makes them more suitable for industrial and environmental purposes $(\mathrm{Ca}$ ñas and Camarero, 2010; Camarero et al., 2014). 
Many studies reported that laccase activity could be enhanced during the degradation of several recalcitrant chemicals such as 4-n-nonylphenol and aniline (Mougin et al., 2002), 2,5-xylidine (Kollmann et al., 2005; Garcia et al., 2006 ), bisphenol A and diclofenac (Yang et al., 2013; Nguyen et al., 2014 ) or nonylphenol (Kim et al., 2008)

In this paper we studied the potential of fungal laccases to degrade BPA, analyzing by gas chromatography-mass spectrometry (GC-MS) the biodegradation pattern of this compound.

\section{Materials and Methods}

\subsection{Reagents}

BPA [2,2-Bis-(4-hydroxyphenyl)propane]) (Cas: 80-05-7) of analytical grade, was purchased from Rankem, India. Silica (60-120 mesh) for the cleaning of samples, N,Obis-(trimethylsilyl) trifluoroacetamide (BSTFA) for silylation and anhydrous sodium sulphate for drying solvent extracts prior to ga s chromatography (GC) analysis, were obtained from Sigma-Aldrich. Ethyl acetate was purchased from Merck.

\subsection{Fungal strains}

The fungal strains used in this study were Coriolopsis gallica (BS54) [KJ412304], Bjerkandera adusta (11B) [KU904462] and Trametes versicolor (A3) [KU904463] isolated in Tunisia. The strains were maintained on Petri plates containing $2 \%$ malt extract agar (MEA) at $4{ }^{\circ} \mathrm{C}$ and sub-cultured every 2 months.

\subsection{Culture conditions}


Fungal strains were cultured in semi-solid-state fermentation conditions in 250$\mathrm{ml}$ cotton-plugged Erlenmeyer flasks containing $5.0 \mathrm{~g}$ of sawdust. The substrate was hydrated with $15 \mathrm{ml}$ of minimal medium (MM), adjusting $\mathrm{pH}$ with $25 \mathrm{mM}$ acetate buffer $\mathrm{pH}$ 5.0. This $\mathrm{MM}$ contained $\left(\mathrm{g}^{-1}\right)$ : glucose, 5; casein peptone, 6; $\mathrm{KH}_{2} \mathrm{PO}_{4}, 0.025$; $\mathrm{MgSO}_{4} 7 \mathrm{H}_{2} \mathrm{O}, 0.25 ; \mathrm{KCl}, 0.5$. Inoculation was carried out directly in Erlenmeyer flasks. Six plugs (diameter $3 \mathrm{~mm}$ ) from 5-day-old fungal cultures on malt extract agar (MEA) plates were added to each Erlenmeyer as inoculum. After fungal growth, the cultures were supplemented with $150 \mathrm{mM}$ CuSO ${ }_{4}$ sterile solution as laccase-inducer. The Erlenmeyer flasks were incubated statically for 12 days under an air atmosphere at $30{ }^{\circ} \mathrm{C}$ and $90 \%$ humidity, to avoid evaporation, in complete darkness. At the end of cultivation time the flasks content was extracted with sodium acetate buffer ( $\mathrm{pH}$ 5.0, $10 \mathrm{mM}$ ) under shaking for $1 \mathrm{~h}$, filtered and centrifuged at $7000 \mathrm{rpm}$ for $20 \mathrm{~min}$ at 4 ${ }^{\circ} \mathrm{C}$. The supernatant was collected and lyophilized to be used as biocatalyst for BPA degradation.

\subsection{Enzyme activity assay}

Laccase activity was measured using $10 \mathrm{mM}$ 2,6-DMP in $100 \mathrm{mM}$ sodium tartrate buffer, $\mathrm{pH} 5.0$ by monitoring the absorbance at $469 \mathrm{~nm}$ using a 6705 JENWAY UV-Vis spectrophotometer $\left(\varepsilon_{469 \mathrm{~nm}}=27500 \mathrm{M}^{-1} \mathrm{~cm}^{-1}\right)$ (Muñoz et al., 1997).

\subsection{Bisphenol A degradation}

BPA (0.01\%) was incubated in a reaction mixture containing $1.0 \mathrm{U} \mathrm{ml} \quad{ }^{-1}$ of the tested fungal laccases in $100 \mathrm{mM}$ sodium acetate buffer $\left(\mathrm{pH} \mathrm{5.0)}\right.$ at $45^{\circ} \mathrm{C}$ under shaking. The enzymatic reaction was allowed to take place for $24 \mathrm{~h}$, and then it was 
stopped increasing the $\mathrm{pH}$ of the solution to 8.0 by adding sodium hydroxide. A BPA sample without added enzymes was treated simultaneously to be used as control. The reaction catalyzed by C. gallica (KJ412304) laccase in the presence or absence of a redox mediator, $1 \mathrm{mM}$ hydroxybenzotriazole (HBT), was incubated for $3 \mathrm{~h}$ and the oxidative degradation products of bisphenol A were identified by GC-MS.

\subsection{Extraction and derivatization}

All samples were extracted twice with 2 volumes of ethyl acetate. The extracted solution was dehydrated with anhydrous sodium sulfate and concentrated by rotary evaporation. Triplicate aliquots of this solution were withdrawn and $5 \mu$ of $0.01 \%$ isotopically labeled BPA in the same solvent were added as internal standard, drying with a gentle nitrogen stream. Before GC-MS analysis, samples were trimethylsilylated (TMS) at $50{ }^{\circ} \mathrm{C}$ for 30 min using $0.2 \mathrm{ml}$ of the BSTFA reagent.

\subsection{BPA degradation products analysis by GC-MS}

After derivatization, the low molecular weight compounds extracted from the BPA control sample and the laccase treatments were identified and quantified using a gas chromatograph equipped with a $\mathrm{n} \mathrm{HP-5MS}$ column $(30 \mathrm{~m} \times 0.25 \mathrm{~mm}$ internal diameter; $0.25 \mu \mathrm{M}$ film thickness) coupled to a quadrupole mass detector (GC-MS system 7980A-5975C, Agilent Technologies). Helium was the carrier gas at a flow rate of $1.2 \mathrm{ml} \mathrm{min}^{-1}$. Injector and detector were programmed at $320 \quad$ o. The column temperature was maintained at $50{ }^{\circ} \mathrm{C}$ for $1.5 \mathrm{~min}$, increased to $150^{\circ} \mathrm{C}$ at $10^{\circ} \mathrm{C} \mathrm{min}^{-1}$, then to $300^{\circ} \mathrm{C}$ at $20^{\circ} \mathrm{C} \mathrm{min}{ }^{-1}$, and held at $300^{\circ} \mathrm{C}$ for 6 min. BPA and HBT were identified by comparison of their retention times and mass spectra with those of 
commercial standards. Data were simultaneously acquired in full scan and SIM modes. Each full scan mass spectrum, recorded in the $\mathrm{m} / \mathrm{z}$ range $33-800 \mathrm{amu}$ (atomic mass units), was searched in the Wiley-NIST2011 database for compounds identification. SIM data were used for BPA quantification to determine the conversion rates. The SIM peak area from the five most abundant ions of the TMS ether derivative of BPA was referred to the area of the peak of ions $m / z 73,217,368$, 369 , and 386 amu characteristic of the TMS ether derivative of the internal standard. Relying on this information, a calibration curve was constructed in the range of 0.25$2.5 \mu \mathrm{g} \mathrm{m} \mathrm{m}^{-1}$.

\section{Results and discussion}

\subsection{Biodegradation of BPA by fungal laccases}

The removal of BPA by different enzyme preparations from different fungal strains was performed at $\mathrm{pH} 5$ and $45^{\circ} \mathrm{C}$. Fig. 1 shows the time course of BPA (0.01\%) removal of in the presence of $1 \mathrm{U} \mathrm{ml}^{-1}$ laccase and $1 \mathrm{mM}$ mediator.

After $1 \mathrm{~h}$ of treatment with C. gallica laccase, more than $62 \%$ of the BPA was removed from the solution. A decrease of $85 \%$ of BPA concentration was achieved after $2 \mathrm{~h}$ and $100 \%$ after $4 \mathrm{~h}$. This reaction proceeded more slowly when catalyzed by laccases from the other strains. BPA removal after $1 \mathrm{~h}$ was lower than $50 \%$, but $100 \%$ degradation occurred in all cases after $8 \mathrm{~h}$.

In order to identify the BPA biodegradation products, assays with $1 \mathrm{U} \mathrm{ml}^{-1}$ of laccases from different fungal strains were carried out in Erlenmeyer flasks. Control samples without added enzymes and enzymatically treated (24 h) BPA samples were analyzed by GC-MS after extraction with ethyl acetate and derivatization ( Fig. 2). In 
review of the current methods for the BPA analytical determination in environmental, food and biological matrices, gas- or liquid-chromatography with mass spectrometric detection (GC-MS and LC-MS, respectively) would provide the best opportunity to obtain the desired detection limit and to identify the products from their mass spectra (Cabana et al., 2007; Han et al., 2015).

Since GC analysis of low volati lity polar compounds, lik e phenolic and acidic compounds, results in poor sensitivity (Szyrwi ńska et al., 2007), derivatization methods have been extensively used including methylation, acetylation and silylation (Gatidou et al., 2007 ; Vi ñas and Campillo, 2014 ), which have frequently been resorted to the identification and quantification of BPA traces. Control reactions confirmed that BPA transformation was due to the laccase catalytic action. The chromatogram of the control sample showed the BPA peak, with retention time $\left(R_{t}\right)$ of $14.4 \mathrm{~min}$ and the mass spectrum characteristic of this compound (Fig. 3). A second peak that eluted at $10.6 \mathrm{~min}$, with a major ion of $\mathrm{m} / \mathrm{z} 263$ (Fig. 3), and that also appeared in the chromatograms of laccase-treated samples, may be considered as an undesirable BPA byproduct formed by the sodium hydroxide add ition to stop the reactions. Oku et al. (2000) reported that the treatment of polycarbonate pellets (PC) in ethylene glycol (EG) with a catalytic amount of $\mathrm{NaOH}(0.1$ equiv) produced BPA monohydroxyethyl ether. In our case, the database identified this product as 2,6-ditert-butylphenol, which agrees with data reported by Verevkin (1999) suggesting that the degradation of alkylphenols may lead to the formation of tert-butylphenol.

The chromatograms depicted in Fig. 2 show that $t \quad$ he BPA peak virtually disappeared after the laccase treatments for $24 \mathrm{~h}$, while new peaks, corresponding to reaction products, were detected. When comparing the chromatograms of the 
extracted compounds, a similar profile was obser ved in reactions catalyz ed by laccases from the B. adusta and T. versicolor isolates ( Fig. 2 a and 2 b), with one predominant product $(\mathrm{Rt}=8.8 \mathrm{~min})$ resulting from BPA oxidation. When the catalyst was the $C$. gallica enzyme, a major peak was detected at $\mathrm{Rt}=7.0 \mathrm{~min}$, indicating that the BPA oxidation mechanism of this laccase was not the same. Probably these laccases have different catalytic and kinetic properties, which deserve to be further studied

Among the laccases assayed in the present study, the one from C. gallica gave the highest BPA removal (91\%) at the end of the oxidative reaction (24 h), as compared to those of B. adusta (85\%) and T. versicolor (72\%). These results agree with those reported by Cabana et al. (2009), who demonstrated that $3.75 \mathrm{U}$ of immobilized laccases from C. polyzona remove BPA. A similar trend toward the biotransformation of BPA by fungal laccases was reported by many authors (Kim and Nicell , 2006; Cabana et al., 2007; Lloret et al., 2012).

After library-search of their full scan mass spectra in the Wiley-NIST2011 database, the final BPA degradation products were identified as glycerol for the laccases of B. adusta and T. versicolor, and $\beta$-hydroxybutyric acid, in the case of the reaction with $C$. gallicalaccase. The mass spectra of the main peaks detected in the chromatograms are presented in Fig. 3.

\subsection{Identification of the intermediates of BPA transformation by laccase/mediator} system

Mediators are known to increase the substrate range of laccases (Kudanga et al., 2011). In this study, $1 \mathrm{mM}$ of 1-hydroxybenzotriazole (HBT) was used as mediator and 
tested to improve the BPA elimination.

Reactions ( $3 \mathrm{~h}$ ), catalyzed by C. gallica laccase, and control samples (without enzyme in the presence (+HBT) or absence of HBT (-HBT) ) were analyzed by GC-MS (Fig. 4).

The profile in Fig. 4c shows a strong reduction of the BPA peak by action of $1 \mathrm{U} \mathrm{ml}^{1}$ of C. gallica laccase and the appearance of the other peaks that may correspond to BPA degradation products, since they are not present in the control chromatogram(Fig. 4a). Our data also show that the HBT peak (9.6 min) disappeared (Fig. 4d), indicating that this compounds is also oxidized and transformed.

In order to understand the BPA biodegradation process by $C$. gallica laccase, the identification of intermediate products originating from BPA degradation was attempted after GC-MS and library search, and the results are summarized in Table 1. Four intermediates with shorter retention time than BPA are gathered in Table 1. Some of those compounds have been identified as BPA degradation products such as carboxylic or polycarboxylic acids (tartaric acid and $\beta$-hydroxybutyric acid). However, hydrocinnamic acid and 3-phenyl-3-hydroxy propanoic acid are similar to the lignin metabolites (Pareek et al., 2001). So probably these compounds were from the culture medium and they were brought into the BPA-degradation system with fungal laccases.

Known intermediates that are more toxic than BPA but were not detected in this study are: $p$-hydroxyacetophenone, $p$-hydroxybenzaldehyde, $p$-hydroxybenzoic acid, hydroquinone, and phenol ( Ike et al., 2002; Lu et al., 2013). It is interesting to notice that all the identified compounds after the BPA biodegradation by laccase from $C$. 
gallica are known as non toxic intermediates in industry of polycarbonate and waste plastics. According to Rameshwari and Meenakshisundaram (2013), $\beta$-hydroxybutyric acid is the precursor to polyesters, which are biodegradable plastics.

CG-MS data a nalysis revealed the accumulation of acidic oxidation intermediates. In a recent review of the BPA degradation products, Husain and Qayyum (2013) reported that the treatment of BPA by biological and enzymatic methods produced such polycarboxylic acids and other transformation products.

As mentioned above, the chromatogram of the reaction products from laccase reaction was markedly different following BPA treatment by the laccase/HBT system, since the mediator is also oxidized giving other degradation products and byproducts. For example, tartaric acid detected upon this reaction, as well as a compound tentatively identified as pyroglutamic acid might have risen this from HBT degradation.

Based on the intermediate products identified here, a schematic view of the pathways for BPA degradation by C. gallica laccase was proposed (Fig. 5).

BPA oxidative cleavage results in the formation of $\beta$-hydroxybutyric acid in the absence of HBT, and of tartaric acid in the presence of HBT. The formation of tartaric and $\beta$-hydroxybutyric acids might be the result of the oxidation of the methyl groups on the propane moiety of BPA molecule under laccase action. Organic acids which commonly found as metabolic pathways intermediates are usually formed following ring fusion of aromatics (Spivack et al., 1994).

\section{Conclusion}

The experimental data suggest that bisphenol $A$ is biodegradable by action of fungal 
laccases.

\section{Acknowledgments}

This work was supported by the Ministry of Higher Education, Scientific Research (Tunisia) and the Comunidad de Madrid project S2013/MAE-2907. The authors thanks Mr Abdelmajid Dammak (National school of engineering of Sfax) for language revision of the manuscript 


\section{References}

Cabana, H., Alexandre, C., Agathos, S.N., Jones, J.P., 2009. Immobilization of laccase from the white rot fungus Coriolopsis polyzona and use of the immobilized biocatalyst for the continuous elimination of endocrine disrupting chemicals. Bioresource Technol. 100, 3447-3458.

Cabana, H., Jiwan, J. L.H., Rozenberg, R., Elisashvili, V., Penninckx, M., Agathos, S.N., Agathos, S.N., Jones, J.P., 2007. Elimination of endocrine disrupting chemicals nonylphenol and bisphenol $\mathrm{A}$ and personal care product ingredient triclosan using enzyme preparation from the white rot fungus Coriolopsis polyzona. Chemosphere 67, 770-778.

Cañas, A.I., Camarero, S., $2010 . \quad$ Laccases and their natural mediators:

Biotechnological tools for sustainable eco-friendly processes. Biotechnol. Adv. $28,694-705$

Chairin, T., Nitheranont, T., Watanabe, A., Asada, Y., Khanongnuch, C., Lumyong, S., 2013. Biodegradation of Bisphenol A and Decolorization of Synthetic Dyes by Laccase from White-Rot Fungus, Trametes polyzona. Appl. Biochem. Biotechnol. 169, 539-545.

Chen, J., Huang, X., Lee, D., 2008. Bisphenol A removal by membrane bioreactor, Process Biochem. 43, 451-456.

Claus, H., Faber, G., König, H., 2002. Redox-mediated decolorization of synthetic dyes by fungal laccases. Appl. Microbiol. Biotechnol. 59, 672-678.

Eio, E.J., Kawai, M., Tsuchiya, K., Yamamoto, S., Toda, T., 2014. Biodegradation of 
bisphenol A by bacterial consortia. Int. Biodeter. Biodegr. 96, 166-173.

Ferro Orozco, A.M., Lobo, C.C., Contreras, E.M., Zaritzky, N.E., 2013. Biodegradation of bisphenol $A(B P A)$ in activated sludge batch reactors: Analysis of the acclimation process. Int. Biodeter. Biodegr. 85, 392-399.

Fischer, J., Kappelmeyer, U., Kastner, M., Schauer, F., Heipieper, H.J., 2010. The degradation of bisphenol A by the newly isolated bacterium Cupriavidus basilensis JF1 can be enhanced by biostimulation with phenol. Int. Biodeter. Biodegr. 64, 324-330.

Flint, S., Markle, T., Thomson, S., Wallace, E., 2012. Bisphenol A exposure effects and policy; a wildlife perspective.J. Environ. Manag. 104, 19-34.

Fukuda, T., Uchida, H., Takashima, Y., Uwajima, T., Kawabata, T., \& Suzuki, M. 2001. Biochem. Bioph. Res. Co. 284, 704-706.

Garcia, T.A., Santiago, M.F., Ulhoa, C.J., 2006. Properties of laccases produced by Pycnoporussanguineus induced by 2,5-xylidine. Biotechnol.Lett. 28; 633-636.

Gatidou, G., Thomaidis, N.S., Stasinakis, A.S., Lekkas, T.D., 2007. Simultaneous determination of the endocrine disrupting compounds nonylphenol, nonylphenol ethoxylates, triclosan and bisphenolA in wastewater and sewage sludge by gas chromatography-mass spectrometry. J. Chromatogr. A. 1138, 3241.

Gianfreda, L., lamarino, G., Scelza, R., Rao, M.A., 2006. Oxidative catalysts for the transformation of phenolic pollutants: a brief review. Biocatal. Biotransform. $24,177-187$. 
Han, Q., Wang, H., Dong, W., Liu, T., Yin, Y., Fan, H., 2015. Degradation of bisphenol A by ferrate (VI) oxidation: Kinetics, products and toxicity assessment. Chem. Eng. J. 262, 34-40.

Huang, Q., Weber, J.W., 2005. Transformation and removal of bisphenol A from aqueous phase via peroxidase-mediated oxidative coupling reactions: efficacy, products, and pathways. Environ. Sci. Technol. 39, 6029-6036.

Husain, Q., Qayyum, S., 2013. Biological and enzymatic treatment of bisphenolA and other endocrine disrupting compounds: a review. Crit. Rev. Biotechnol. 33, 260-292.

Ike, M., Chen, M.Y., Jin, C.S., Fujita, M., 2002. Acute toxicity mutagenicity and estrogenicity of biodegradation products of bisphenol A. Environ. Toxicol. 17, 457-461.

Kamaraj, M., Sivaraj, R., Venckatesh, R., 2014. Biodegradation of Bisphenol A by the tolerant bacterial species isolated from coastal regions of Chennai, Tamil Nadu, India. Int. Biodeter. Biodegr. 93, 216-222.

Kim, Y., Yeo, S., Song, H.G., Choi, H.T., 2008. Enhanced Expression of Laccase during the degradation of Endocrine Disruption Chemicals in Trametes versicolor. J. Microbiol. 46; 402-407.

Kim, Y.J. Nicell, J.A., 2006. Laccase-catalyzed oxidation of bisphenol A with the aid of additives.Process Biochem. 41, 1029-1037.

Kollmann, A., Boyer, F.D., Ducrot, P.H., Kerhoas, L., Jolivalt, C., Touton, I., Einhorn, J., Mougin, C. , 2005. Oligomeric compounds formed from 2,5-xylidine (2,5dimethylaniline) are potent enhancers of laccase production in Trametes 
versicolor ATCC 32745. Appl Microbiol. Biotechnol. 68, 251-258.

Kudanga, T., Nyanhongo, G.S., Guebitz, G.M., Burton, S., 2011. Potential applications of laccase-mediated coupling and grafting reactions: A review. Enzyme Microb. Tech. 48, 195-208.

Kuo, C.Y., Wu, C.H., Wu, J.T., Chen, Y.R., 2014. Synthesis and characterization of a phosphorus-doped TiO2 immobilized bed for the photodegradation of bisphenol A under UV and sunlight irradiation. Reac. Kinet. Mech. Cat. DOI 10.1007/s11144-014-0783-2.

Li, H., Zhao, H., Liu, C., Li , Y., Cao, H., Zhang, Y., 2013. A novel mechanism of bisphenolA removal during electro-enzymatic oxidative process: Chain reactions from self-polymerization to cross-coupling oxidation. Chemosphere $92,1294-1300$.

Lloret, L., Eibes, G., Feijoo, G., Moreira, M.T., Lema, J.M., 2012. Degradation of estrogens by laccase from Myceliophthora thermophila in fed-batch and enzymatic membrane reactors. J. Hazard. Mater. 213, 175-183.

Lu, N., Lu, Y., Liu, F., Zhao, K., Yuan, X., Zhao, Y., Li, Y., Qin Zhu, H.J., 2013. $\mathrm{H}(3) \mathrm{PW}(1)(2) \mathrm{O}(4)(0) / \mathrm{TiO}(2)$ catalyst-induced photo-degradation of bisphenol A (BPA): kinetics, toxicity and degradation pathways. Chemosphere 91, 12661272.

Margot, J., Maillard, J., Rossi, L., Barry, D.A., Holliger, C., 2013. Influence of treatment conditions on the oxidation of micropollutants by Trametes versicolor laccase. New Biotechnol. 30, 803-813.

Michałowicz, J., 2014. Review or Mini-review Bisphenol A- Sources, toxicity and biotransformation. Environ. Toxicol. Phar. 37, 738-758. 
Mohapatra, D.P., Brar, S.K., Tyagi, R.D., Surampalli, R.Y., $2010 . \quad$ Physico-chemical pretreatment and biotransformation of wastewater and wastewater sludgefate of bisphenol A. Chemosphere.78, 923-941.

Mohapatra, D.P., Brar, S.K., Tyagi, R.D., Surampalli, R.Y., 2011. Concomitant degradation of bisphenol A during ultrasonication and Fenton oxidation and production of biofertilizer from wastewater sludge. Ultrason. Sonochem. 18, 1018-1027.

Mougin, C., Kollmann, A., Jolivalt, C., 2002. Enhanced production of laccase in the fungus Trametes versicolor by the addition of xenobiotics. Biotechnol. Lett. 24, 139-142.

Mueller, J.K., Heger, S., 2013. Endocrine disrupting chemicals affect the Gonadotropin releasing hormone neuronal network. Reprod. Toxicol. 44, 7384.

Muñoz, C., Guill én, F., Mart ínez, A.T., Mart ínez, M.J., 1997. Laccase isoenzymes of Pleurotus eryngii: Characterization, catalytic properties and participation in activation of molecular oxygen and $\mathrm{Mn}^{2+}$ oxidation. Appl. Environ. Microbiol. 63, 2166-2174.

Nguyen, L.N., Hai, F.I., Price, W.E., Leusch, F.D.L., Roddick, F., McAdam, E.J., Magram, S.F., Nghiem, L.D., 2014.Continuous biotransformation of bisphenol A and diclofenac by laccase in an enzymatic membrane reactor. Int. Biodeter. Biodegr. 95, 25-32.

Nie, Y., Qiang, Z., Ben, W., Liu, J., 2014. Removal of endocrine-disrupting chemicals and conventional pollutants in a continuous-operating activated sludge 
process integrated with ozonation for excess sludge reduction Chemosphere. $105,133-138$.

Nitheranont, T., Watanabe, A., Suzuki, T., Katayama, T., Asada, Y., 2011.

Decolorization of synthetic dyes and biodegradation of bisphenol A by laccase from the edible mushroom, Grifola frondosa. Biosci. Biotech. Bioch. 75, 18451847.

Oku, A., Tanaka, S., Hata, S., 2000. Chemical conversion of poly(carbonate) to bis(hydroxyethyl) ether of bisphenol A. An approach to the chemical recycling of plastic wastes as monomers. Polymer. 40, 6749-6753.

Pareek, S., Azuma, J.I., Matsui, S., Shimizu Y., 2001. Degradation of lignin and lignin model compound under sulfate reducing condition. Water Sci Technol. 44, 351-358.

Rameshwari, R., Meenakshisundaram, M., 2013.A review on bacterial polyesterpolyhydroxyalkanoate. Int. J. Recent Sci. Res. 4, 1781-1788.

Reddy, C.A., 1995.The potential for white-rot fungi in the treatment of pollutants. Curr. Opin. Biotechnol. 6, 320-328.

Rodríguez-Couto, S., Toca Herrera, J.L., $2006 . \quad$ Industrial and biotechnological applications of laccases: A review. Biotechnol. Adv. 24, 500-513.

Spivack, J., Leib, T.K., Lobos, J.H., 1994. Novel pathway for bacterial metabolism of bisphenol A. Rearrangements and stilbene cleavage in bisphenolA metabolism. J. Biol. Chem. 269, 7323-7323.

Sun, Y., Huang, H., Sun, Y., Wang, C., Shi, X-L., Hu, H-Y., Kameya, T., Fujie.K., 2013.Ecological risk of estrogenic endocrine disrupting chemicals in sewage 
plant effluent and reclaimed water. Environ. Pollut. 180, 339-344.

Szyrwińska, K., Kolodziejczak, A., Rykowska, I., Wasiak, W., Lulek, J., 2007.

Derivatization and gas chromatography-low-resolution mass spectrometry of bisphenol A. Acta Chromatogr. 18, 49-58.

Tan, Y.H., Goh, P.S., Ismail, A.F., 2015. Development of photo-catalytic coupled zinciron oxide nanoparticles via solution combustion for bisphenolA removal. Int. Biodeter. Biodegr. 102, 346-352.

Tanaka, T., Yamada, K., Tonosaki, T., Konishi, T., Goto, H., Taniguchi, M., 2000.Enzymatic degradation of alkylphenols, bisphenol A, synthetic estrogen and phthalic ester. Water Sci. Technol. 42, 89-95.

Viñas, P., Campillo, N., 2014. Gas Chromatography-Mass Spectrometry Analysis of Polyphenols in Foods (Book Chapter). Polyphenols in Plants: Isolation, Purification and Extract Preparation by Ronald Ross Watson, English pp 103157.

Wang, X.D., Lv, Y., Liu, H.Y., Li, M.M., 2014. Removal of bisphenol A from water by ozone. Adv. Mat. Res. 864-867, 155-160.

Yang, S., Hai, F.I., Nghiem, L.D., Nguyen, L.N., Roddick, F., Price, W.E., 2013. Removal of bisphenol A and diclofenac by a novel fungal membrane bioreactor operated under non-sterile conditions. Int. Biodeter. Biodegr. 85, 483-490.

Yaropolov, A.I., Skorobogatko, O.V., Vartanov, S.S., Varfolomeyev, S.D., 1994.Laccaseproperties, catalytic mechanism, and applicability. Appl. Biochem. Biotechnol. 49, 257-280.

Yu, L., Wang, C., Ren, X., Sun, H., 2014. Catalytic oxidative degradation of bisphenol A 
using an ultrasonic-assisted tourmaline-based system: Influence factors and mechanism study. Chem. Eng. J. 252, 346-354. 


\section{FIGURE CAPTIONS}

Fig. 1. Elimination of $0.01 \%$ of BPA with $1 \mathrm{U} \mathrm{ml} \quad{ }^{-1}$ laccase from $(\square)$ C. gallica , $(\Delta) T$. versicolor and $(\bullet)$ B. adusta at $\mathrm{pH} 5.0$ and $45^{\circ} \mathrm{C}$.

Fig. 2. GC-MS analysis of the compounds extracted with ethyl acetate from $24 \mathrm{~h}$ reactions of BPA with $1 \mathrm{U} \mathrm{ml}^{-1}$ of fungal laccases from: a) B. adusta; b) T. versicolor; c) C. gallica and d) Control sample of BPA without enzyme.

Fig. 3. Mass spectra of peaks at: a) Rt: $14.3 \mathrm{~min}(\mathrm{BPA}), \mathrm{b}) \mathrm{Rt}: 10.6 \mathrm{~min}$, attributed to a byproduct of BPA that may result from addition of sodium hydroxide, c) Rt: 8.1 min, the major product from treatment with laccases from $\quad$ B. adusta and $T$. versicolor glycerol, and d) Rt: 7.0 min, the main compound obtained by treatment with $C$. gallica laccase identified as $\beta$-hydroxy-butyric acid.

Fig. 4. Chromatograms showing the degradation of $0.01 \%$ of BPA. Negative controls: a) BPA without laccase and HBT, b) BPA and HBT without laccase. Reactions ( $3 \mathrm{~h}$ ) catalyzed by $1 \mathrm{U} \mathrm{ml}^{-1}$ of $C$. gallica laccase: c) without HBT, and d) with $1 \mathrm{mM} \mathrm{HBT}$.

Fig. 5. Pathways for the BPA degradation by C. gallica laccase. 
Fig. 1 


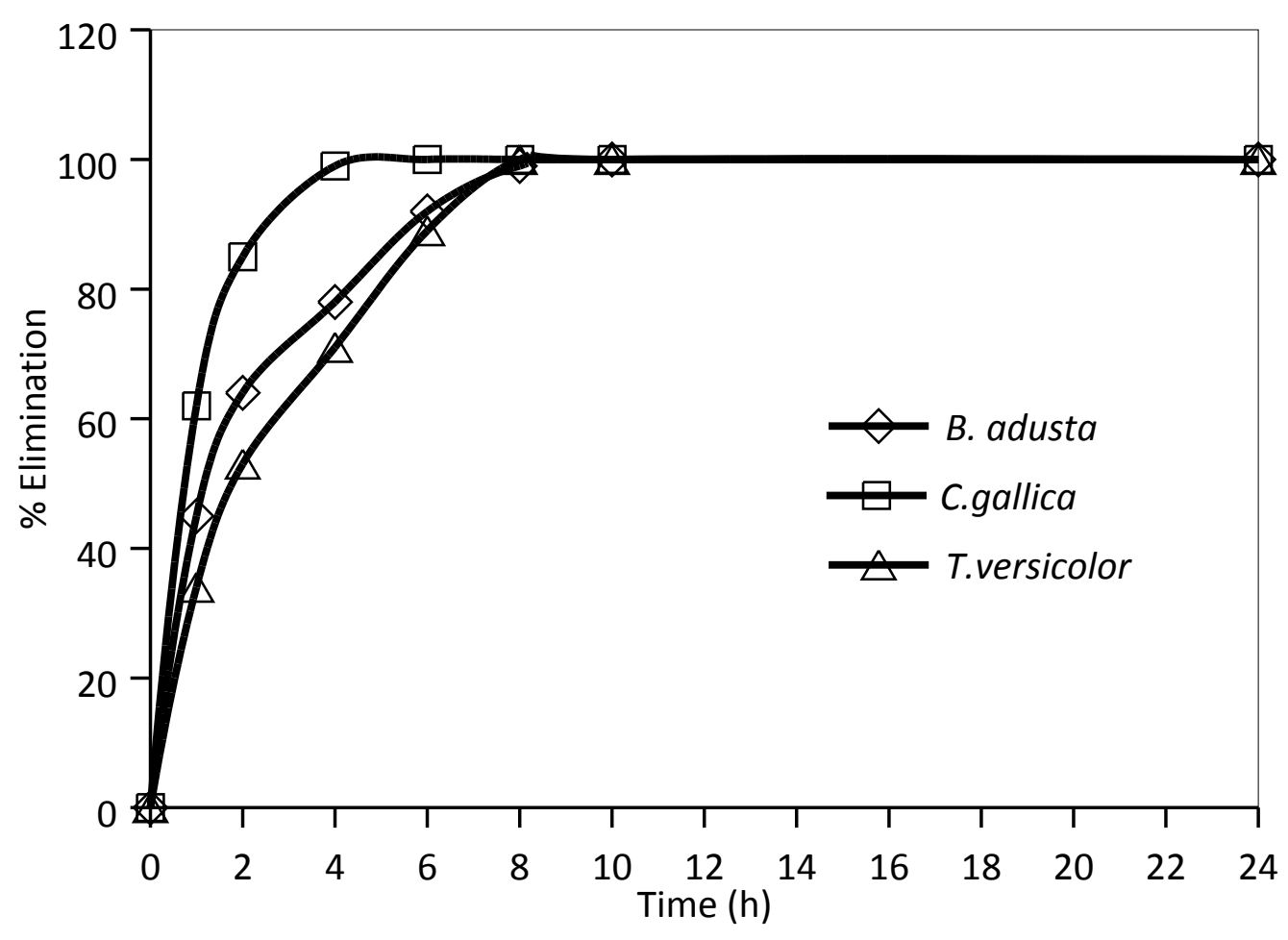

Fig 2 

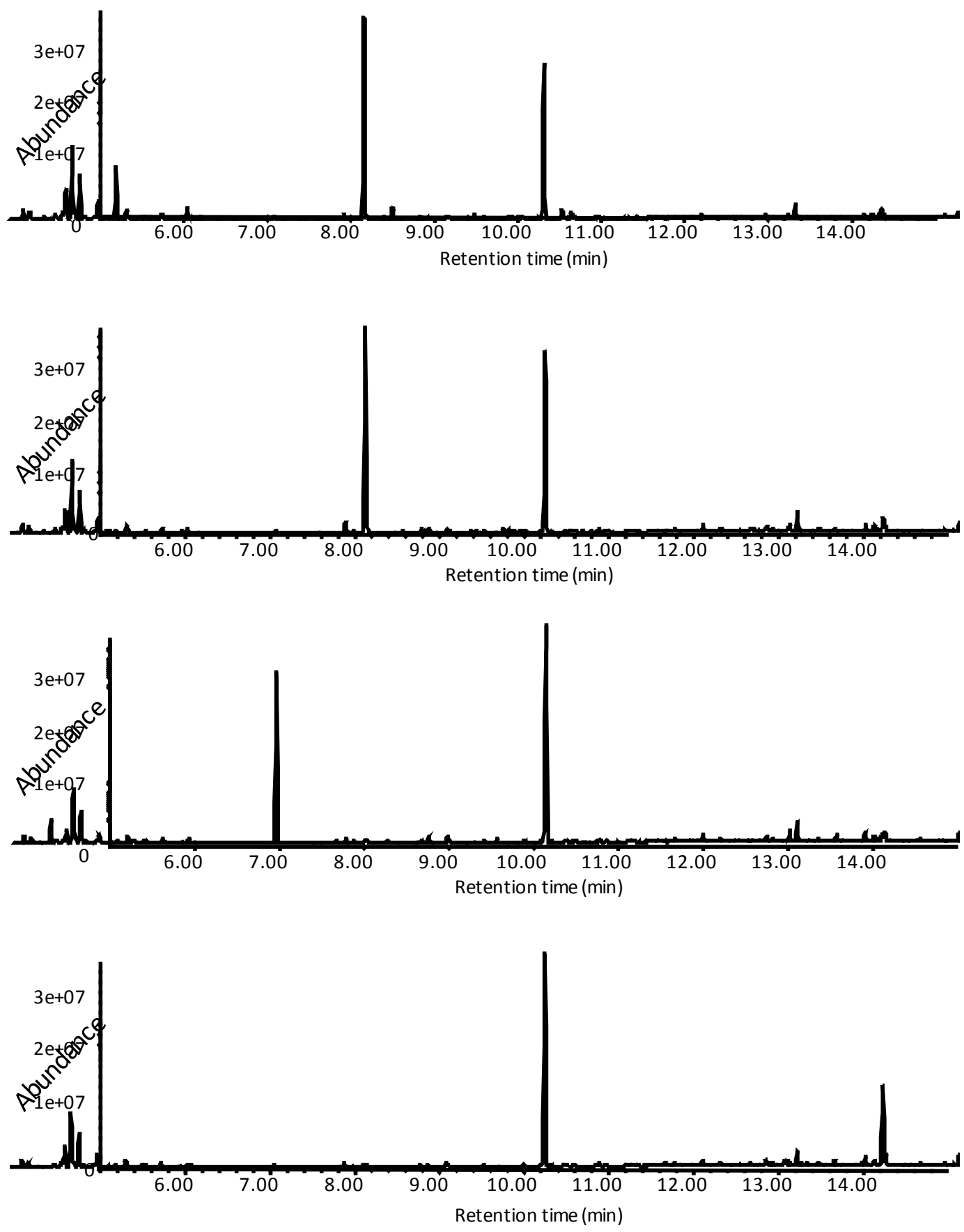
Fig 3 

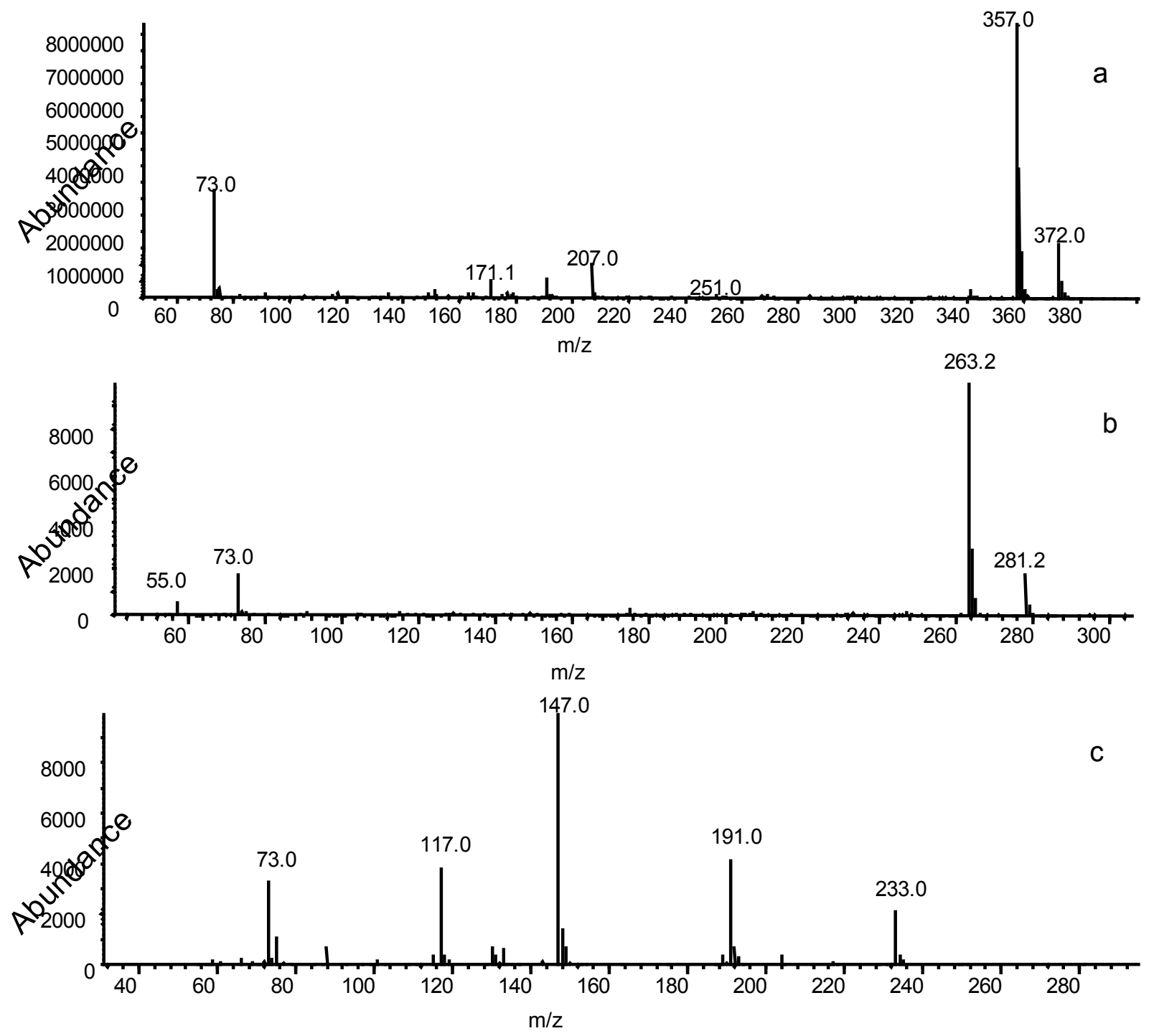

d

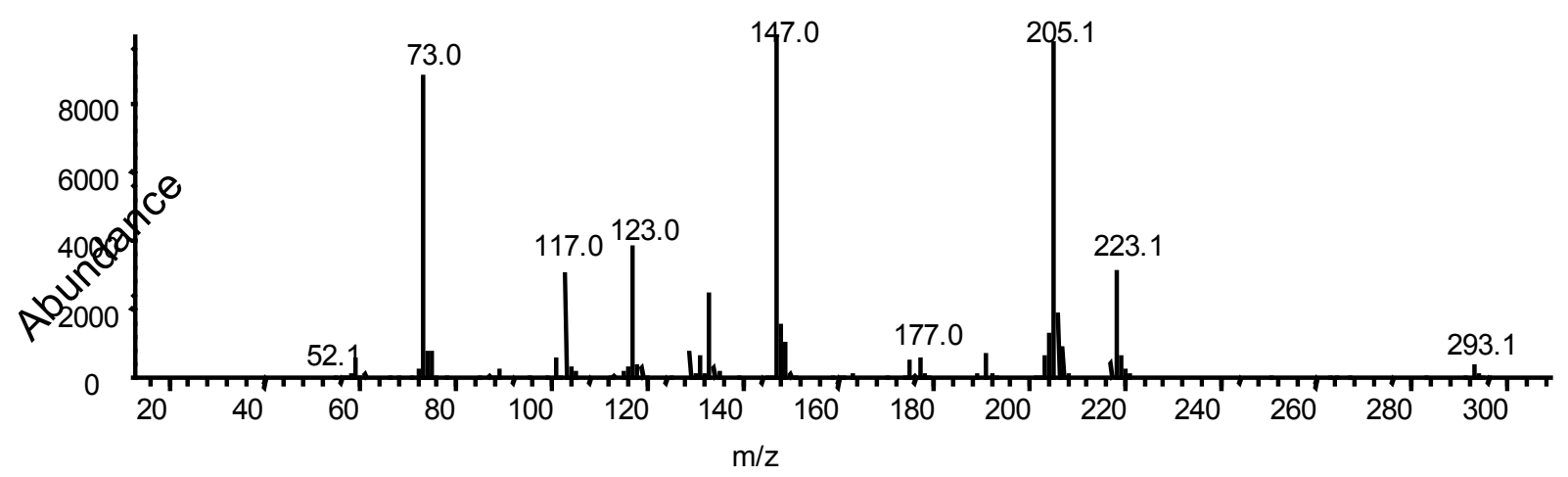

Fig 4 

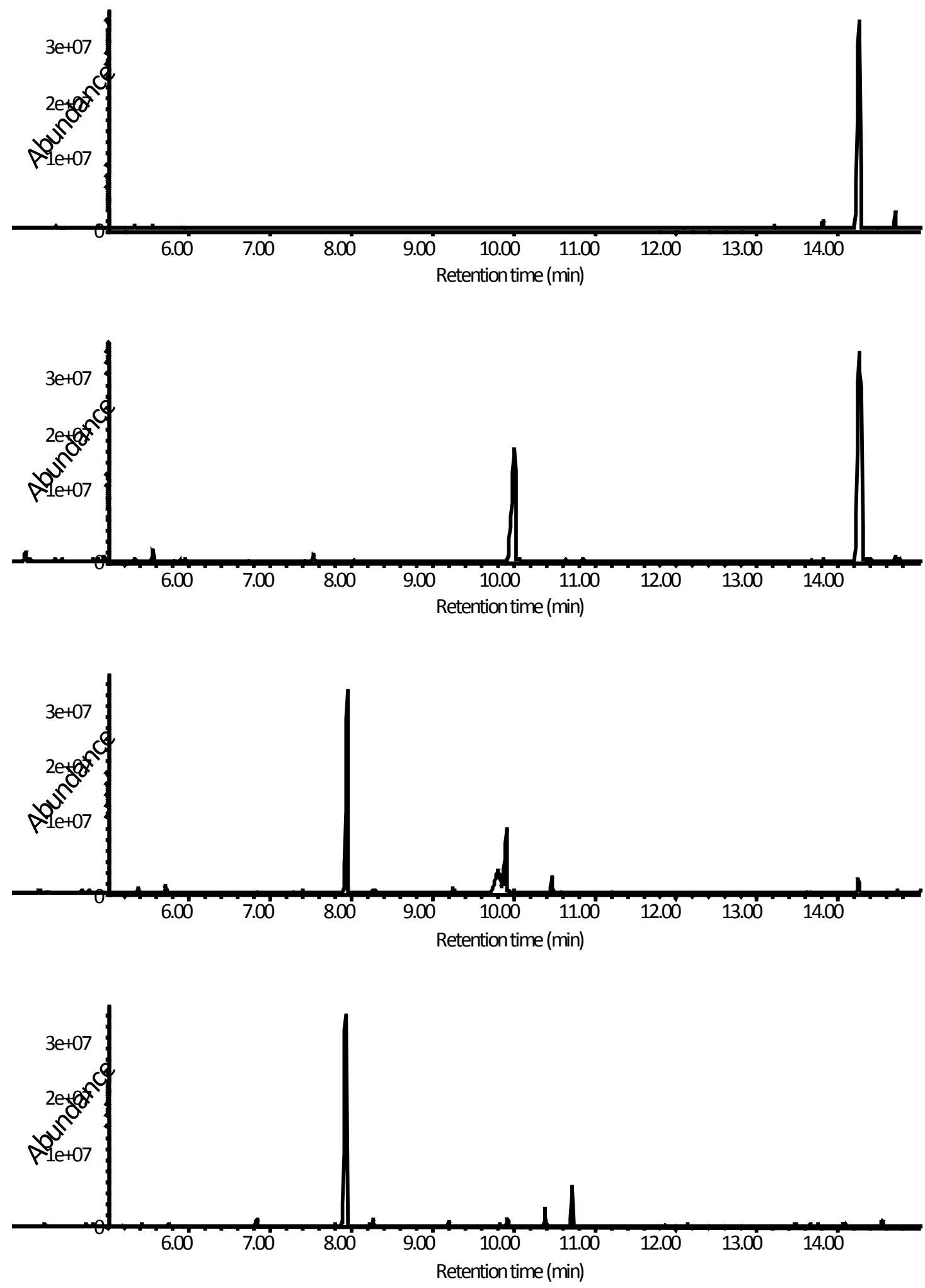
Fig 5

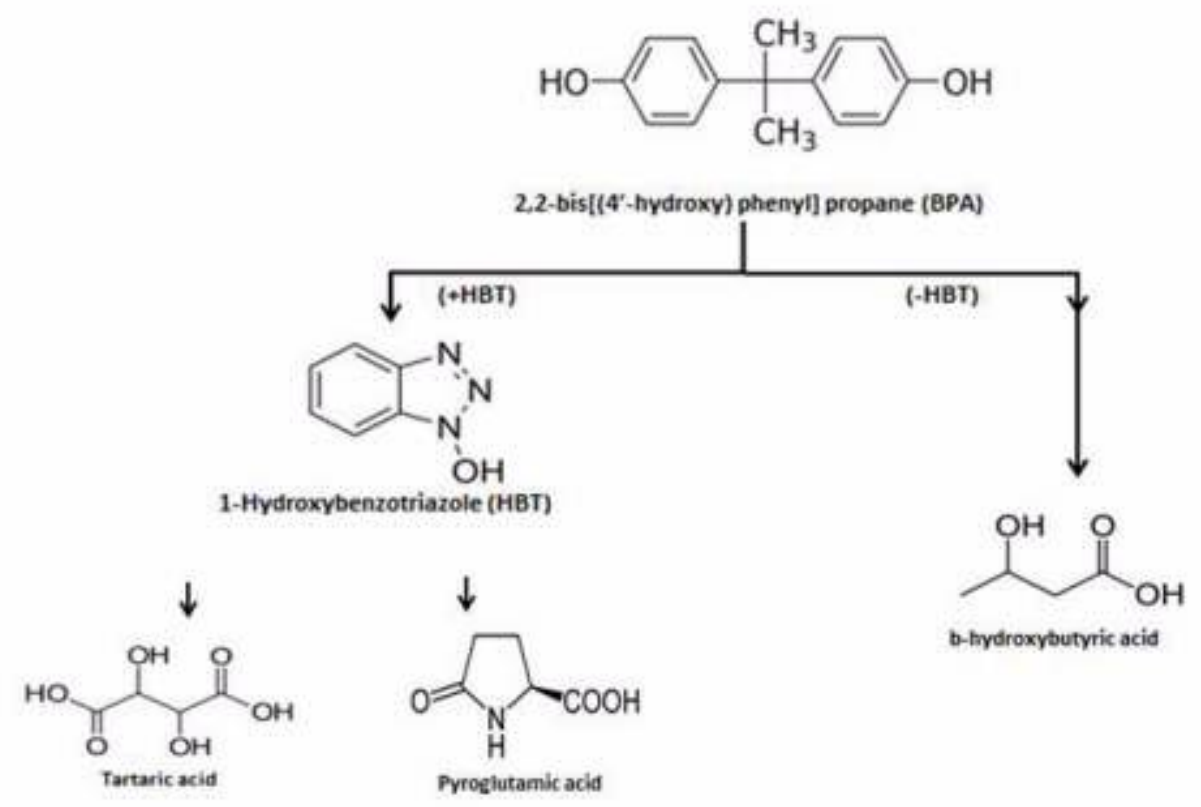

